\title{
PT Freeport Indonesia - The transition to underground production
}

\author{
T Casten Freeport-McMoRan, United States \\ M Johnson PT Freeport Indonesia, Indonesia \\ C Zimmer PT Freeport Indonesia, Indonesia \\ M Mahayasa Freeport-McMoRan, United States
}

\begin{abstract}
This paper will discuss the production history, current challenges and the future plans for the PT Freeport Indonesia (PTFI) minerals district as it transitions from primarily open-pit production to a series of large volume caving mines. The Grasberg open pit commenced mining in 1989 and completed at the end of 2019, having mined over 1.37 billion tonnes of ore and having produced 27 billion Ibs of payable copper as well as 46 million ozs of payable gold. In addition to the ore mined, the pit also moved over 3.4 billion tonnes of overburden during this timeframe. This paper discusses the rapid mining process, challenges encountered and the pivotal role the Grasberg open pit played in supporting the future underground era. PTFI has been cave mining since the 1980s and has ramped up production over time with a series of progressively deeper mining horizons in the East Ertsberg Skarn System (EESS). Currently, the Deep Ore Zone (DOZ) mine is in active production and is the third lift in the EESS. In 2004, an access development named the $A B$ Adits commenced at a mining horizon approximately $500 \mathrm{~m}$ below the DOZ mine. This allowed the fourth lift in the EESS, the Deep MLZ (DMLZ) mine to be constructed. The DMLZ initiated caving in 2015 and is currently ramping up production. In addition, the AB Adits allowed timely access to the downward extension of the Grasberg ore body, and the Grasberg Block Cave mine initiated caving in 2018 and is also undergoing a rapid production ramp-up. These long-lived, high-volume caving operations will extend the life of the mineral district past 2040 with a plan to produce approximately 200 - $250 \mathrm{ktpd}$ at peak production rates. The paper will discuss the strategic plans applied to construct these large and long-lead projects and some of the challenges faced during the 16 years of pre-production, cave initiation and production ramp up. Critical topics such as rapid access, infrastructure construction, ground control, wet muck mitigation and seismicity are discussed in the paper, focusing on lessons learned and ongoing improvements.
\end{abstract}

\section{Introduction}

PTFI operates in the remote highlands of the Sudirman Mountain Range in the province of West Papua, Indonesia, which is on the western half of the island of New Guinea. The mine site experiences around $5 \mathrm{~m}$ of rain per annum. Operations have been in place since 1967 with production commencing in 1973 from the Ertsberg Open pit. The Grasberg minerals district has a history of rapid expansion due to an aggressive exploration program that has driven the mine plan.

The PTFI minerals district has been primarily an open-pit operation but has had a significant underground mining component from a series of caving operations that began in the 1980s. As the pit reached the end of its economic life in 2019, the district production has transitioned to total underground operation with production from several large underground mines currently ramping up to fill the available processing capacity. 
The operation at PTFI employs 28,000 people and is a self-sufficient operation that provides everything from power, aviation, schools, housing and hospitals to the employees and local communities.

The strategic plan for the transition from pit to underground era commenced in 2002 with a series of prefeasibility studies that set the overall direction and timeline of the transition. It was recognized that these long-lived, large volume underground caving operations would require a significant lead-time to construct and that any delays to the schedule would significantly impact value.

The first access for the UG expansion was initiated in September 2004 when the AB Adit portals were blasted. Although a series of mine access and construction projects commenced in 2004, it is important to note that the PTFI team had been operating underground mines since the 1980s and that the DOZ mine was ramping up very rapidly during this period. This provided a lot of internal experience that was available to help design and build the future operations. The PTFI operation currently has four underground mines in production; the Deep Ore Zone (DOZ), the Deep Mill Level Zone (DMLZ), the Grasberg Block Cave (GBC) and the Big Gossan (BG) stoping mine.

The Grasberg minerals district has both throughput and timing constraints driven by infrastructure limitations and the current end of the Izin Usaha Pertambangan Khusus (IUPK) or Special Mining Business License with the Government of Indonesia in 2041. The mine has experienced technical, labour and governmental challenges that have significantly impacted the mine development and production schedules. In order to keep the life of mine strategic plan on track, a series of processes were established to provide long-term structure to the project decision-making process. Due to the nature of the longterm projects being undertaken, it was essential that there was a consistent and repeatable process of design, approvals and change management in pace. Regular project status reviews and decision points were essential to control the projects as they progressed.

\section{History and location}

The PTFI minerals district is in the Jayawijaya mountain range on the Western half of the island of New Guinea in the Indonesian province of West Papua. See Figure 1. For over 100 years, explorers had attempted to access and climb the Carstenz Pyramid (named for a Dutch naval navigator in 1620) or as it is locally known, Puncak Jaya. The mountain is over 5,000 $\mathrm{m}$ in height and is proximal to a large equatorial glacier. It was not until the Colijn Expedition in 1936 that climbers reached the peak of this mountain, the highest point between the Andes and the Himalayas.

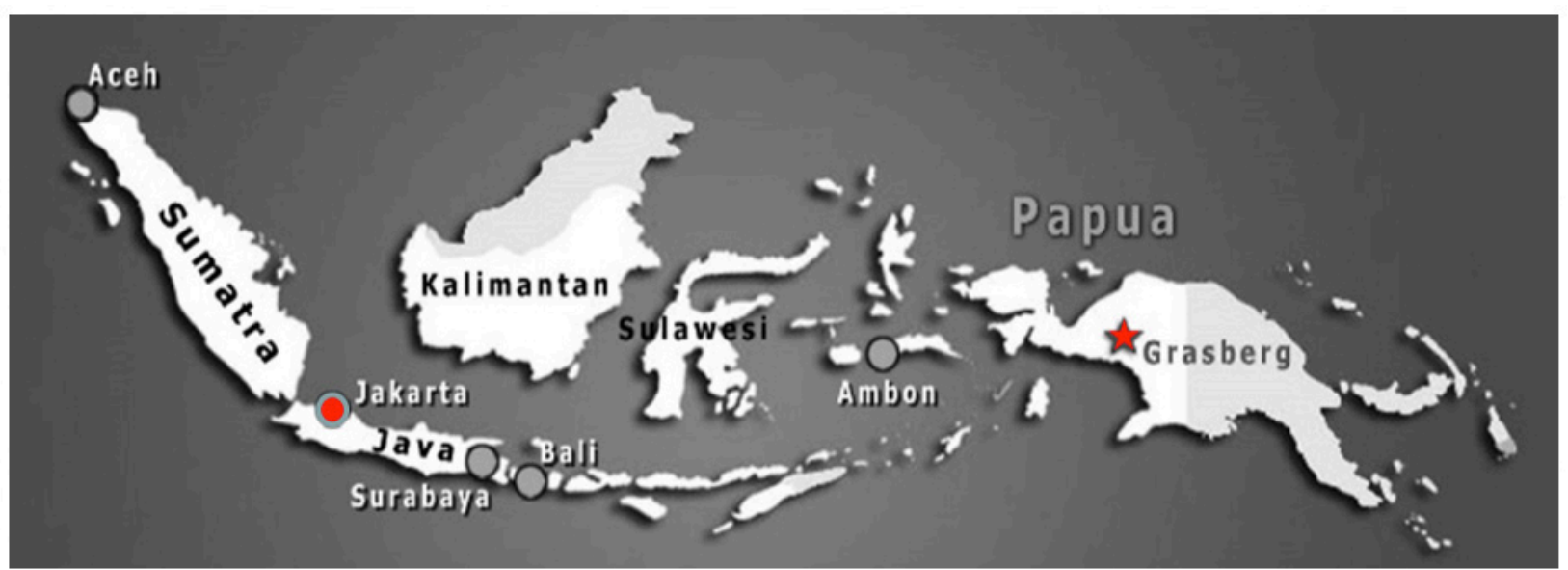

Figure 1 Location of the Grasberg minerals district

On day 55 of the expedition, Jean-Jacques Dozy, a Dutch petroleum geologist, noted a large outcropping of chalcopyrite-rich magnetite skarn at the 3,600-3,800 $\mathrm{m}$ elevation and about $100 \mathrm{~km}$ from the coast. He named this outcrop Ertsberg (Dutch for ore mountain) and took samples, pictures and made sketches 
for his report. Dozy also noted the Grasberg (Dutch for grassy mountain) intrusion, located further up the valley from the Ertsberg (Dozy 1939). Two days later, the team summited Puncak Jaya (See Figure 2). Upon his return to the Netherlands, Dozy submitted his report to his employers. Given the extremely isolated nature of the location and the lack of any infrastructure, the deposit was considered unfeasible and the report placed in the company archives.


Figure 2 The Colijn expedition in 1936 and the Ertsberg and Grasberg Deposits in 1967

In August of 1959 Forbes Wilson of the Freeport Sulphur Company fortuitously came across the report during a visit to the Netherlands. After recognizing the potential value of the deposit, an expedition was rapidly formed and in May of 1960 the team reached West Papua. There followed more detailed exploration efforts and an initial assessment of the Ertsberg reserve was set at 30 million tonnes and 2.5\% Cu (Wilson 1977).

There were significant legal, political and technical challenges to overcome to initiate mining. This was especially true for technical challenges faced by the construction of the $100 \mathrm{~km}$ access road from the coast to the highlands. The Ertsberg open-pit mining began in 1973 and produced $29.3 \mathrm{Mt}$ of ore at 2.33\% Cu and $0.53 \mathrm{~g} / \mathrm{t}$ Au by the time mining ended in 1989.

Shortly after the Ertsberg mining commenced, additional drilling of nearby skarn outcrops identified the potential for an underground mine at the top of a deep trending skarn system now called the East Ertsberg Skarn System (EESS). The initial orebody discovered in the EESS complex was named the Gunung Bijih Timur (GBT), which translated from the Indonesia language meaning East Ertsberg. Mining commenced in the early 1980s in the GBT using caving methods and is detailed below.

Although recognized as a porphyry with potential in the early 1970s the Grasberg open-pit deposit was initially determined to be a relatively low-value porphyry and not pursued further at the time. The report recommended that a deep exploration hole be drilled in the centre of the deposit. The area was revisited in 1985 and a hole drilled. The results were disappointing with grades in the range of $0.3-0.5 \% \mathrm{Cu}$. Unfortunately, the hole had been drilled along strike in a low-grade intrusion that runs through the centre of the Grasberg deposit and post-dates the initial mineralization. An increase in the gold price prompted renewed interest in the Grasberg deposit and in 1988 a five-hole drill program was authorized. All of the holes intersected promising grade material over $1 \% \mathrm{Cu}$ and $1 \mathrm{~g} / \mathrm{t} \mathrm{Au}$, but hole GRS-4 was the significant indicator that this was a major orebody when it intersected over $600 \mathrm{~m}$ of mineralized material at average grades of $1.65 \% \mathrm{Cu}$ and $1.4 \mathrm{~g} / \mathrm{t} \mathrm{Au}$. This is considered the "discovery" hole for the Grasberg mine and prompted additional drilling and ultimately the rapid initiation of mining. In late-1989 open-pit mining commenced.

Figure 3 shows the increase in production tonnes since 1973 and the disposition of ore production from open-pit and underground sources. 


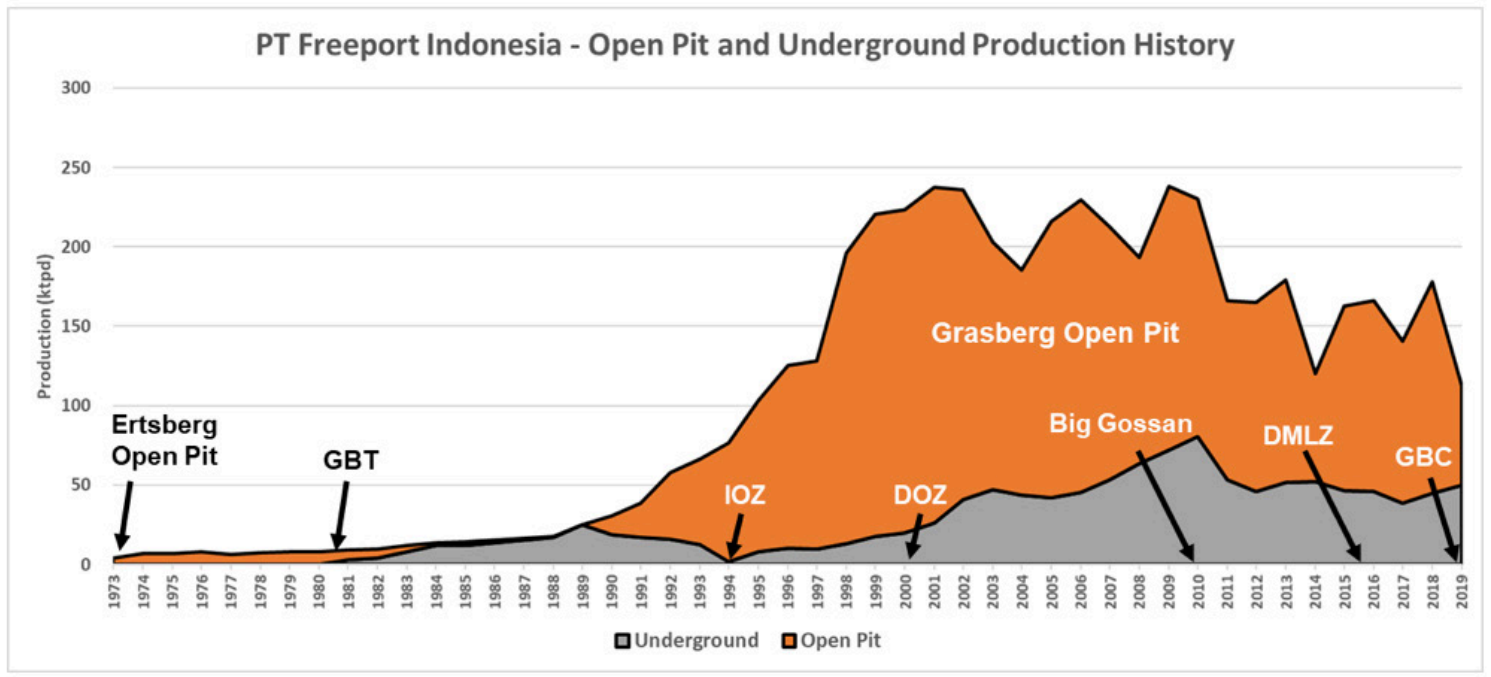

Figure 3 Open Pit and Underground Mine production history at PTFI

\section{$3 \quad$ Reserves}

The PTFI mining district has a history of rapid reserve growth driven by the discovery of the Grasberg open pit and shown in Figure 4. Initial reserves were at $29.3 \mathrm{Mt}$ of ore in 1973 and are currently at 1.87 Bn tonnes at the end of 2018, with payable metal reserves of 35.6 Bn lbs of copper and $29.1 \mathrm{MM}$ ozs of gold (See Table 1).

Table 1 End 2019 10-K Grasberg district reserve summary

\begin{tabular}{|c|c|c|c|c|c|c|}
\hline \multicolumn{2}{|c|}{ End 2019 10-K Reserves } & \multicolumn{2}{c|}{ Grades } & \multicolumn{2}{c|}{ Payable metal } \\
\hline & & $\begin{array}{c}\text { Ore } \\
\text { Tonnes }\end{array}$ & Copper & Gold & Pounds & Troy Ozs \\
\hline Mine & & (millions) & $(\%)$ & $(\mathrm{g} / \mathrm{t})$ & (billions) & (millions) \\
\hline Deep MLZ & DMLZ & 429 & 0.92 & 0.75 & 7.6 & 8.2 \\
\hline Deep Ore Zone & DOZ & 29 & 0.50 & 0.48 & 0.3 & 0.4 \\
\hline Big Gossan & BG & 55 & 2.33 & 0.97 & 2.6 & 1.2 \\
\hline Grasberg Block Cave & GBC & 959 & 0.97 & 0.73 & 17.2 & 14.2 \\
\hline Kucing Liar & KL & 340 & 1.25 & 1.04 & 8.0 & 5.1 \\
\hline Grasberg Open Pit & GRS & 0 & 0.00 & 0.00 & 0.0 & 0.0 \\
\hline Total & & 1,813 & 1.04 & 0.79 & 35.6 & 29.1 \\
\hline
\end{tabular}

From the start of mining in 1973 through 2018, the Grasberg Minerals District has produced approximately $1.8 \mathrm{Bn}$ tonnes of ore containing 36 billion pounds of payable copper and 53 million ounces of payable gold. Figure 4 shows the rapid growth of the reserves over time in terms of payable copper and gold. It is notable that the continued and extensive brownfields exploration program was adding more reserves to the operation every year than was being mined, through to the early 2000s when production began to outpace the exploration program. At this point, the limiting factor to adding more reserves was the Contract of Work end date in 2041 and the mill capacity of $240 \mathrm{ktpd}$. Additional reserves falling outside of these constraints were added to the district resources. This continued growth of reserves was a key factor in driving the future mine plans. 




Figure 4 Payable metal reserve growth and production from 1973-2018

\section{$4 \quad$ PT Freeport Indonesia mining district}

The PTFI minerals district is shown in Figure 5 and shows the locations of the orebodies associated with two main igneous intrusions. The district geology has been well documented by others (Schwarz et al. 2019; Coutts et al. 1999) and is not covered in this paper. Figure 5 demonstrates the spatial separation of the underground operations that affords them the ability to operate independently while still being proximal to exchange personnel and equipment resources as needed.

There are not many other mining districts of this size that allow for access from the base of the orebodies upwards into the mine. Although the topography was a significant challenge to be overcome for the open-pit operations, as previously, noted it adds significant benefits to the underground orebodies in terms of drainage and access.

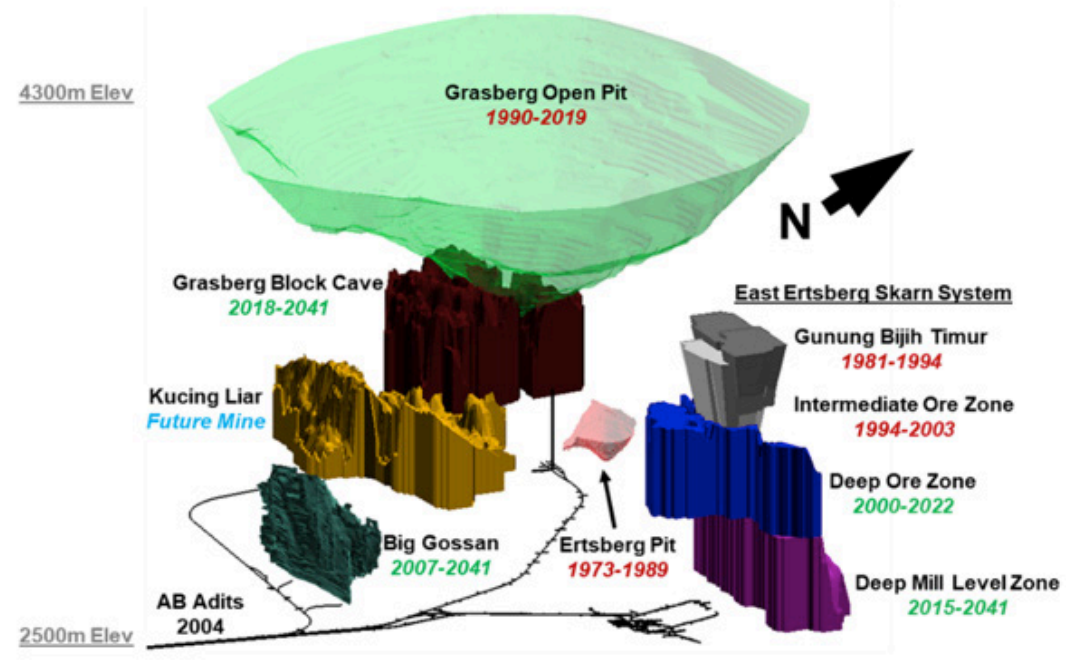

Figure 5 Grasberg minerals district-orebody schematic 


\subsection{Grasberg Open Pit - 1990-2019}

After the discovery of the Grasberg in 1988, there was a period of rapid construction as the deposit was prepared for mining operations to commence. By late 1989, enough infrastructure was in place to allow mining to begin. Up to this point, the Ertsberg and GBT mines had relied upon logistical support and ore handling using several $1.6 \mathrm{~km}$ long, single-span aerial tramways that rose $700 \mathrm{~m}$ from the mill valley up to the GBT area. These provided access for people, materials and equipment up to the mining areas and while other tramways transported the ore down to the mill stockpiles. It quickly became clear that the Grasberg pit expansion program was limited by the tram lifting capacity of 15 tonnes and an alternate access was required to handle the larger surface-mining equipment required.

The Heavy Equipment Access Trail (HEAT Road) was developed between 1990 and 1992 and successfully connected the main access road from the lowlands all the way up to the mining areas. The HEAT Road is extremely steep with numerous switchbacks but allowed the larger equipment to be transported up to the pit. Several contractors were asked to bid the HEAT Road project, but most felt it was too difficult to achieve and either declined or estimated between $\$ 12$ - 15 million to build it. Ultimately, PTFI's team of dozer operators and road builders rose to the challenge led by Pak llyas Hamid, who had taken part in the initial access road construction from the lowlands to the highlands in the 1960s. The PTFI team built the HEAT Road for less than $\$ 2$ million and in a shorter time than originally proposed by the outside contractors. This cleared the way for the rapid ramp-up of production from the Grasberg mine. Figure 6 shows the Grasberg open pit in 1988 and 2019.
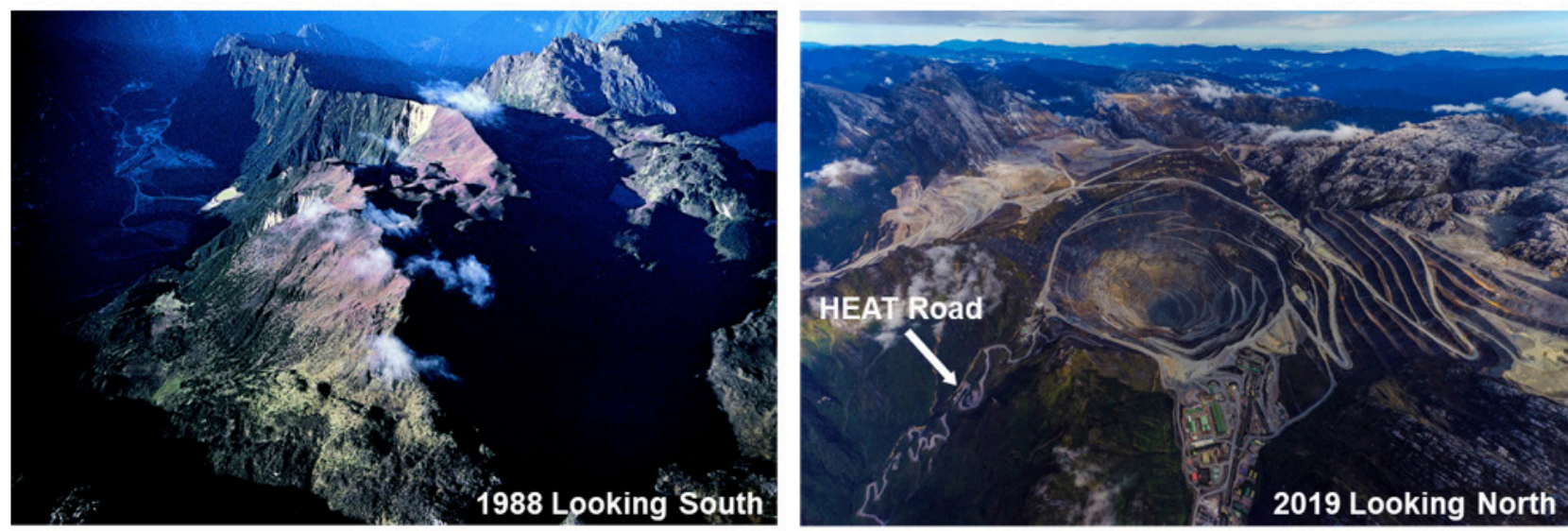

Figure 6 Photographs of the Grasberg open pit in 1988 and 2019

Over the life-of-mine, the Grasberg pit moved 4.8 billion tonnes of rock consisting of 1.37 billion tonnes of ore and 3.46 billion tonnes of overburden with an average stripping ratio of 2.5. At peak production in 2009, the mine moved 263 million tonnes (an average $720 \mathrm{ktpd}$ ) utilizing a fleet of 160 production trucks and 17 shovels.

Figure 7 indicates the life-of-mine production from the Grasberg open pit. The Grasberg pit produced over 27 billion lbs of payable copper and 46 million ounces of payable gold between 1989 and 2019 .

The open pit was successfully extended from a planned closure of mid-2019 through to the end of 2019 and has overlapped with GBC caving activities by a year, which was much longer than originally anticipated. This has allowed the open pit to accelerate a significant amount of metal forward from the reserve into 2019. The cave-pit interaction monitoring, and the open-pit steepening is discussed in detail in separate papers (Widijanto et al. 2020; Mahayasa et al. 2020). 




Figure 7 Grasberg open pit production history

\subsection{Gunung Bijih Timur (GBT) or East Ore Mountain Phase I and II - 1981-1994}

The GBT mines were the first underground operations at PTFI and commenced production in 1981. Gunung Bijih Timur is Indonesian for East Ore Mountain. The GBT Phase I was located at the 3,610 m level and applied a variety of caving methods as shown in Figure 8. Initially designed at a production rate of 5,000 tpd, the GBT mines quickly exceeded this initial nameplate and reached rates of 28,000 tpd. Mining methods evolved over time as newer mining concepts were applied, with a transition from slusher mining and rail haulage to the use of LHDs in the mining process. Between 1981 and 1994 the GBT operations produced 86 million tonnes of ore.

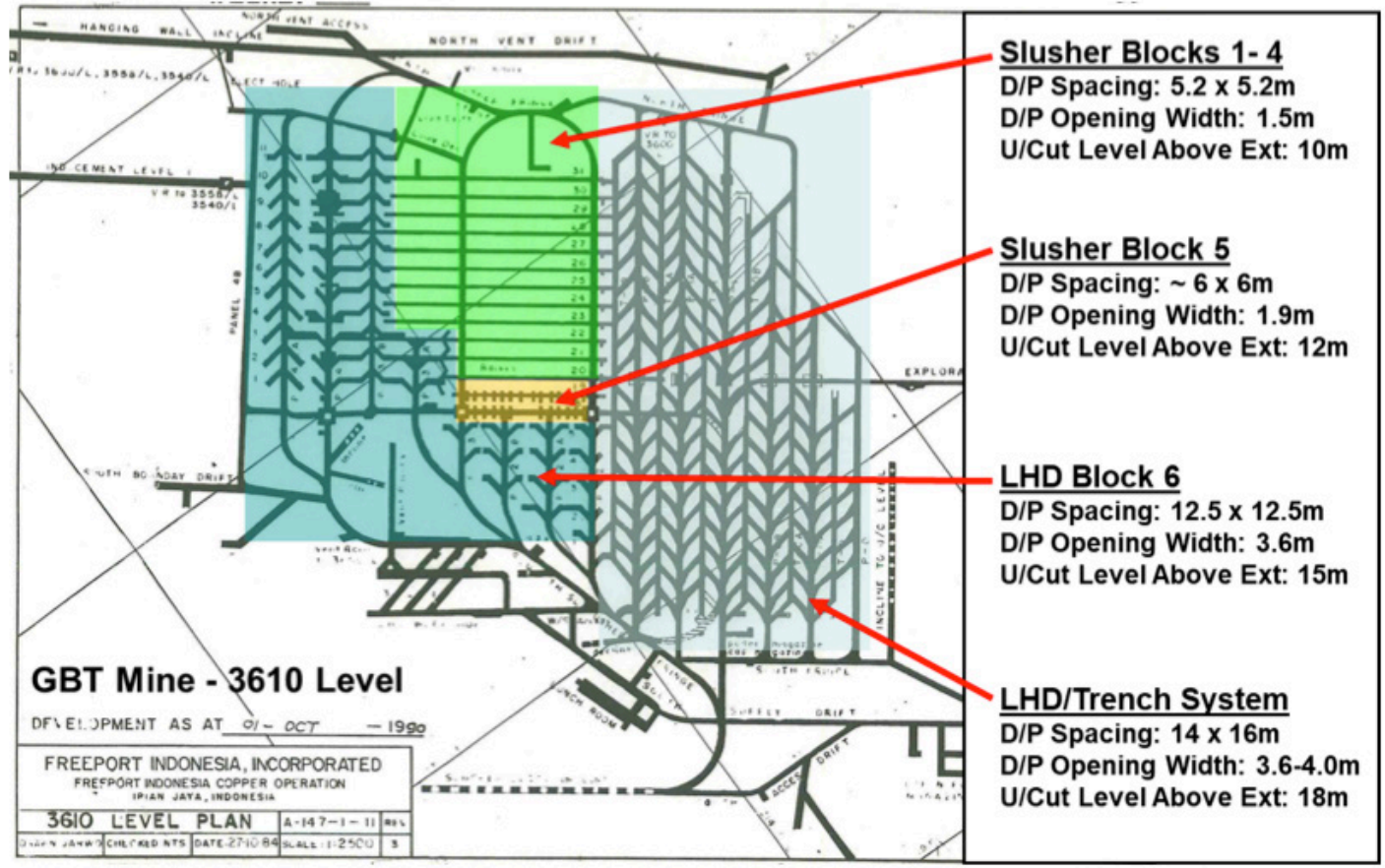

Figure 8 GBT Mine - evolution of cave mining methods 


\subsection{Intermediate Ore Zone (IOZ) -1994- 2003}

In 1994, the IOZ mine initiated production in 1994 with a design production rate of 10,000 tpd. It rapidly surpassed its nameplate capacity and maintained rates at over 19,000 tpd for several years. The IOZ mine utilized a post-undercut mechanized cave mining method. The size of the footprint made for a very simple ventilation and ore handling system with the LHD's tramming the ore to grizzlies located on the fringe. The ore was sized over $400 \mathrm{~mm}$ grizzlies using fixed rock breakers and conveyed to one of two crushers. The IOZ was closed in 2003 when the DOZ cave began to impact the critical fixed facilities. Over the life of the mine, the IOZ produced 47 million tonnes of ore.

The IOZ mine was the first exposure to extensive wet muck and a remote-control system was set up in the underground to operate LHD's and rockbreakers. See Figure 9. A lot of the wet muck processes and procedures were formed during this period, including the wet muck categorization methodology still in use today.
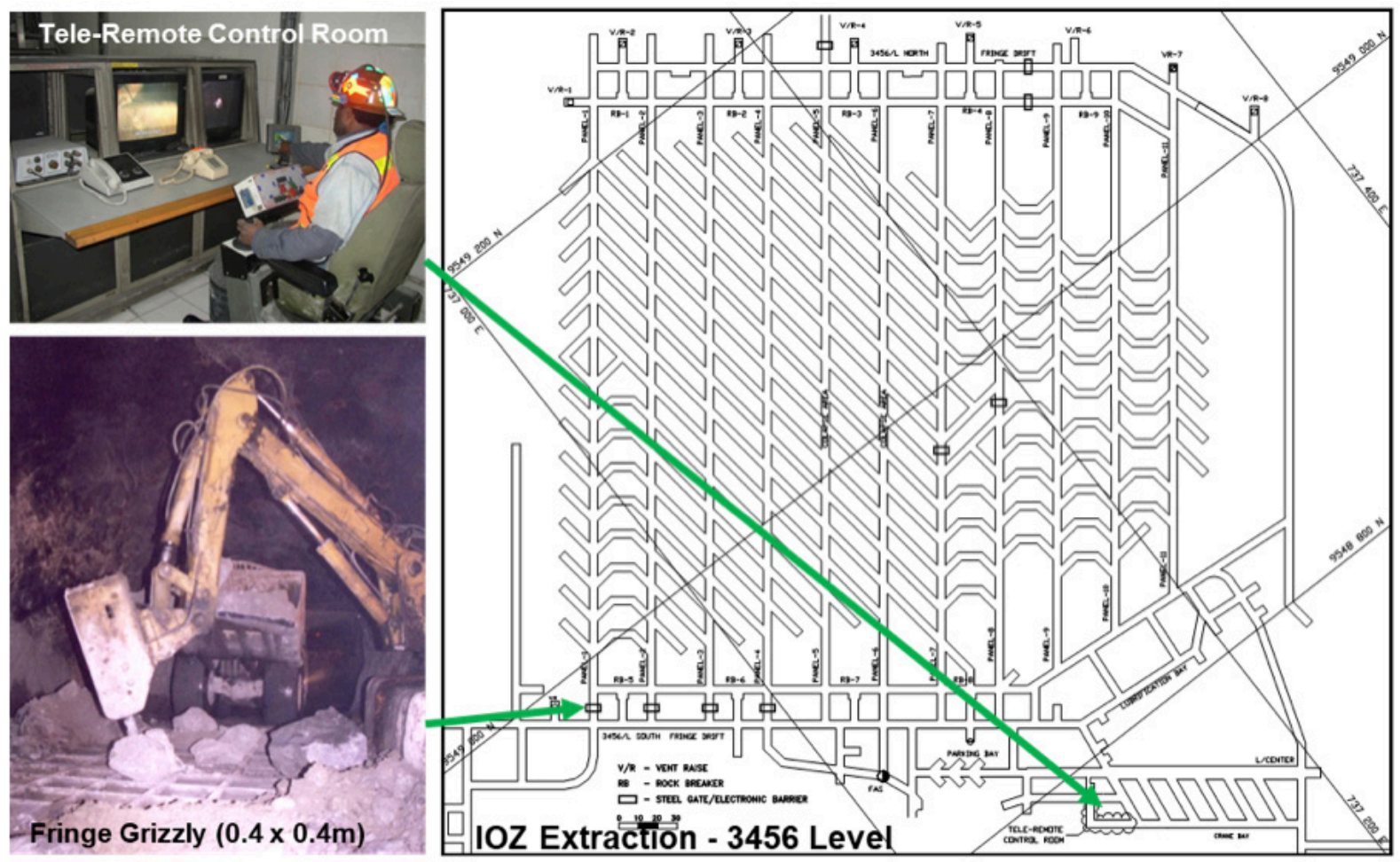

Figure $9 \mathrm{IOZ}$ mine extraction level footprint and early tele-remote-control room

\subsection{Deep Ore Zone (DOZ) - 2000-2022}

The DOZ mine feasibility study was completed in 1998 and caving production began in 2000. Originally designed for a maximum production rate of $25 \mathrm{ktpd}$, based on initial reserves of $96 \mathrm{Mt}$, the DOZ underwent series of continuous expansions as more ore was added to the reserve. At year-end 1998, the DOZ reserve was $130 \mathrm{Mt}$, and by 2008, this had more than doubled to $283 \mathrm{Mt}$, not including the mined ore in the intervening 10-year period.

Based upon initial compelling economics, the DOZ mine development commenced before completion of the feasibility study. It was clear that the schedule was the primary value driver, and this was the focus of the planning and operations teams. The ramp up to $25 \mathrm{ktpd}$ was achieved 18 months ahead of schedule and on budget. An expansion to $35 \mathrm{ktpd}$ was approved before completing the $25 \mathrm{ktpd}$ ramp- 
up. The DOZ was then further expanded to $50 \mathrm{ktpd}$ with a second gyratory crusher and finally to a peak of $80 \mathrm{ktpd}$ in 2010 . The increase from $50 \mathrm{ktpd}$ to $80 \mathrm{ktpd}$ was primarily around accelerating drawpoint openings and some improvements in the ventilation systems. Overall capital expenditure for all of the mine expansions was just under $\$ 450$ million, spent between 2000-2010.

The DOZ achieved sustained production of $80 \mathrm{ktpd}$ in 2010-2011 from a single production block, PB West. From 2011 through 2014, the mine experienced a series of strikes and government mandated export restrictions that resulted in production stoppages and slowdowns. Figure 10 shows the rapid decrease in production beginning in 2011. This unplanned and significant decrease in production led to damage on the extraction and undercut levels from convergence and allowed for an accelerated build up and spread of wet muck throughout the mine. This damage, subsequent repair activities and the early onset of wet muck impacted the mine's ability to continue to produce at the higher rates.

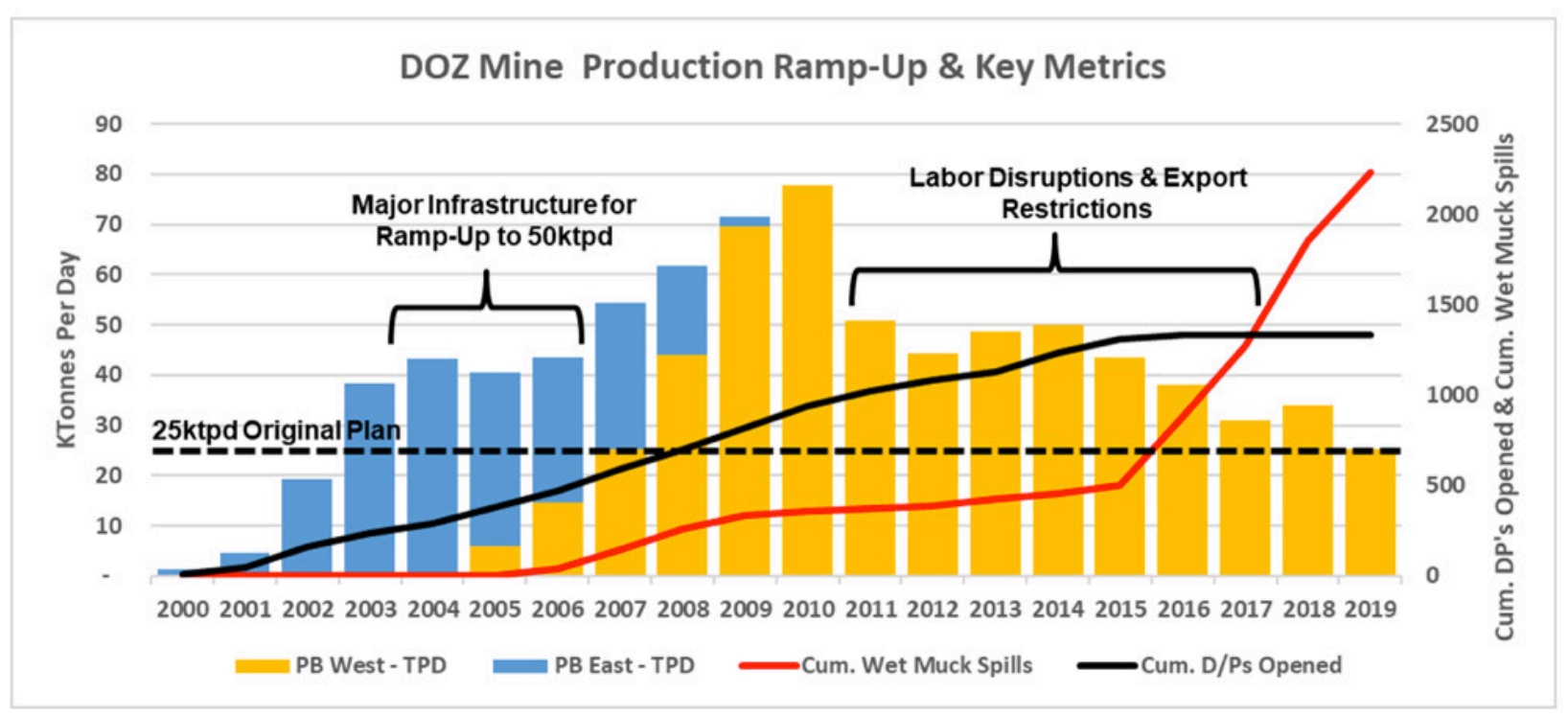

Figure 10 DOZ mine production ramp-up and key metrics

Another significant contributing factor to the rapid increase in wet muck and panel damage was from the poor draw compliance experienced during the ramp up from $50 \mathrm{ktpd}$ to $80 \mathrm{ktpd}$. This uneven draw further exacerbated the onset and magnitude of wet muck spills when the production restrictions seen after 2010 started impacting the mine (Edgar). Mixed sections of the mine were not able to be drawn due to ongoing repair requirements and the imposed tonnage or labour driven constraints. These areas recompacted and were not able to drain effectively. With adjacent mine areas still under draw, this caused an increase in the magnitude and frequency of spills as the water migrated to the zones of draw. There is a marked increase in wet muck spills, beginning in 2015, as the entire footprint had completed undercutting and no more new drawpoints were coming on line while large areas of the footprint began to be closed due to depletion, convergence or excessive wet muck spills.

The management of wet muck has been a dominating factor in the latter part of the DOZ production history and is anticipated in the future underground operations. The experience gained from the DOZ is critical in planning for the future of the underground. The response to the wet muck issue has been the development of the largest LHD automation system in an underground mine. Significant improvements have been made in refining this system by working with the OEM and the PTFI stakeholders.

Over the life-of-mine, the DOZ developed approximately $155 \mathrm{~km}$ of tunnels and opened 1,350 d/ps. Through the end of 2019, the DOZ mine had produced 300 million tonnes of ore, more than three times the original reserve used in the feasibility study. 


\subsection{Big Gossan Mine - 2010-2041}

The Big Gossan mine is an open stope with paste backfill operation located adjacent to the existing mill installation and the HEAT road access to the open pit (See Figure 11). It was historically used as a training area for many years and was then converted into a producing mine. All of the key facilities are located underground with adit access at the bottom and top of the orebody. With the proximity of the mine to the mill valley, it was critical that a non-subsidence causing method was used. All production ore is sent to the 2,500 m level via ore passes, where it is trucked to a crusher and then hoisted up to the existing conveyor system and out to the mill stockpiles. The proximity of the mill operation provides a tailings feed to the paste plant located underground and at the top of the orebody. The $640 \mathrm{~m}$ shaft is for production hoisting only and a spiral ramp connects all of the levels for personnel and materials handling. The Big Gossan is currently producing at its nameplate capacity of 7,000 tpd.

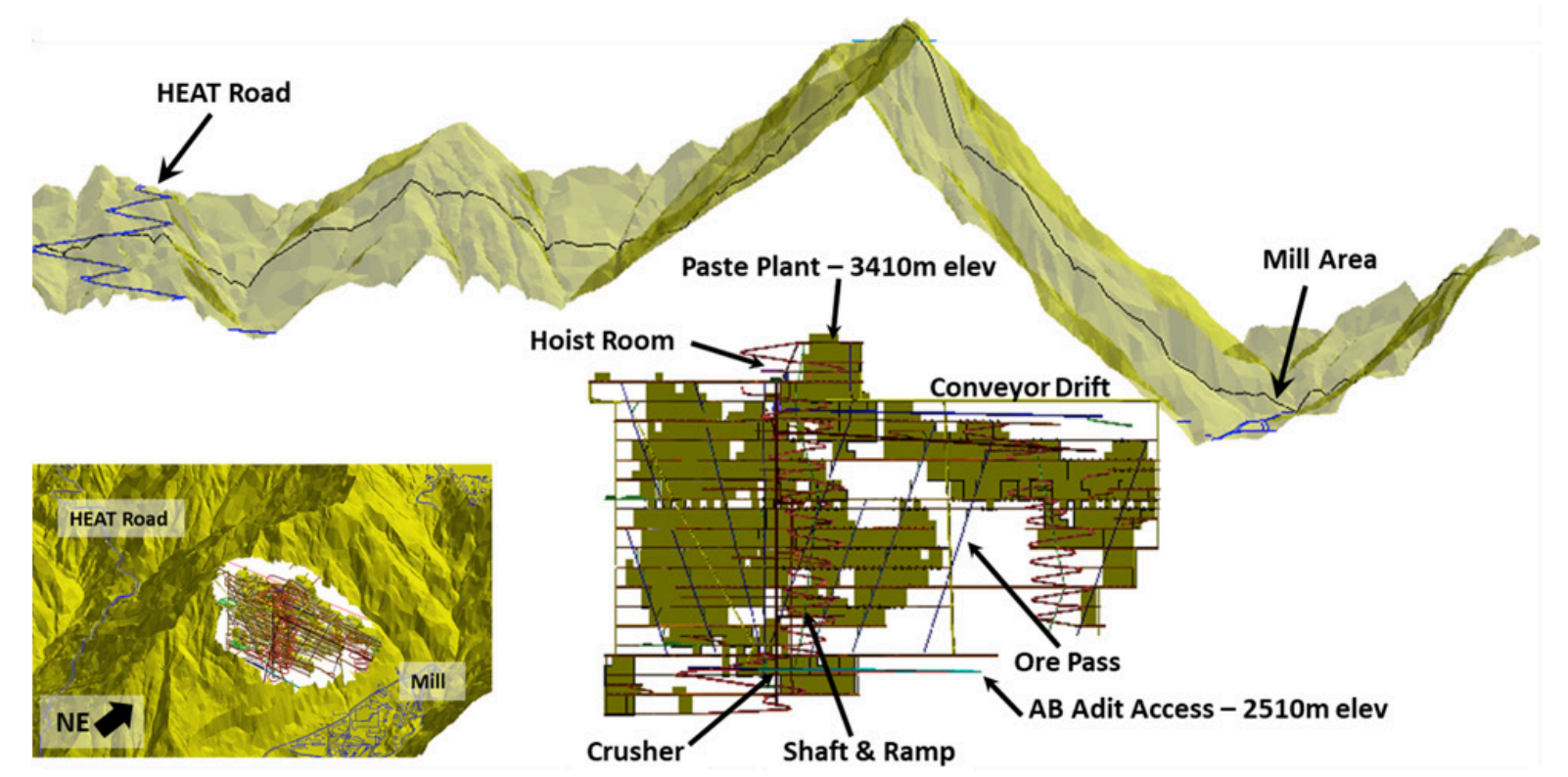

Figure 11 Big Gossan long section looking North-East

\subsection{Kucing Liar Mine (KL) - Timing under review}

The Kucing Liar mine is an additional long-term underground mine development project that has not been initiated yet and is still under study. The $\mathrm{KL}$ is located adjacent to and underneath sections of the GBC mine, see Figure 5 . The KL is planned to be a large capacity caving operation that will add significant production capacity to the district. More than half of the currently identified KL ore falls outside of the 2041 Contract of Work (COW) timeframe and is categorized as a resource. Aggregate long-term capital cost estimates for development of the Kucing Liar ore body are projected to approximate $\$ 3.6$ billion, and the timing of development is under review. Additionally, full development would require $\$ 5.7$ billion of capital expenditures at our processing facilities to optimize the handling of underground ore types. The large combination of reserves and resources provides an opportunity to enhance the value of this project in a manner that could significantly change the mine and processing plans; these trade-off studies are currently underway.

\subsection{Grasberg Block Cave (GBC) - 2018-2041}

Access to the GBC initiated in September 2004 at the $A B$ adits and in early 2006 from existing pit dewatering tunnels located above the GBC footprint. The $A B$ adits are critical to the development of the underground expansion and provide key logistical support for the ramp up. The adits handle personnel and materials and also act as a reliable gravity drainage system. The system of common infrastructure that supports all of the UG mines has been well documented (Hewitt et al. 2008). 
Once the GBC footprint was reached in 2007, the mine underwent a rapid ramp up in development as multiple levels and headings were made available and additional equipment and crews were deployed. During pre-production development, the mine averaged $25 \mathrm{Km}$ of tunnelling per year with a peak over $30 \mathrm{~km}$ in 2016. The total development meters between the two expansion projects (DMLZ and GBC) averaged over $40 \mathrm{~km}$ per year between 2012 and 2019. Figure 12 shows the actual GBC and DMLZ mine development through end 2019 with the key construction milestones shown for GBC. The GBC achieved $280 \mathrm{~km}$ of development through end of 2019.

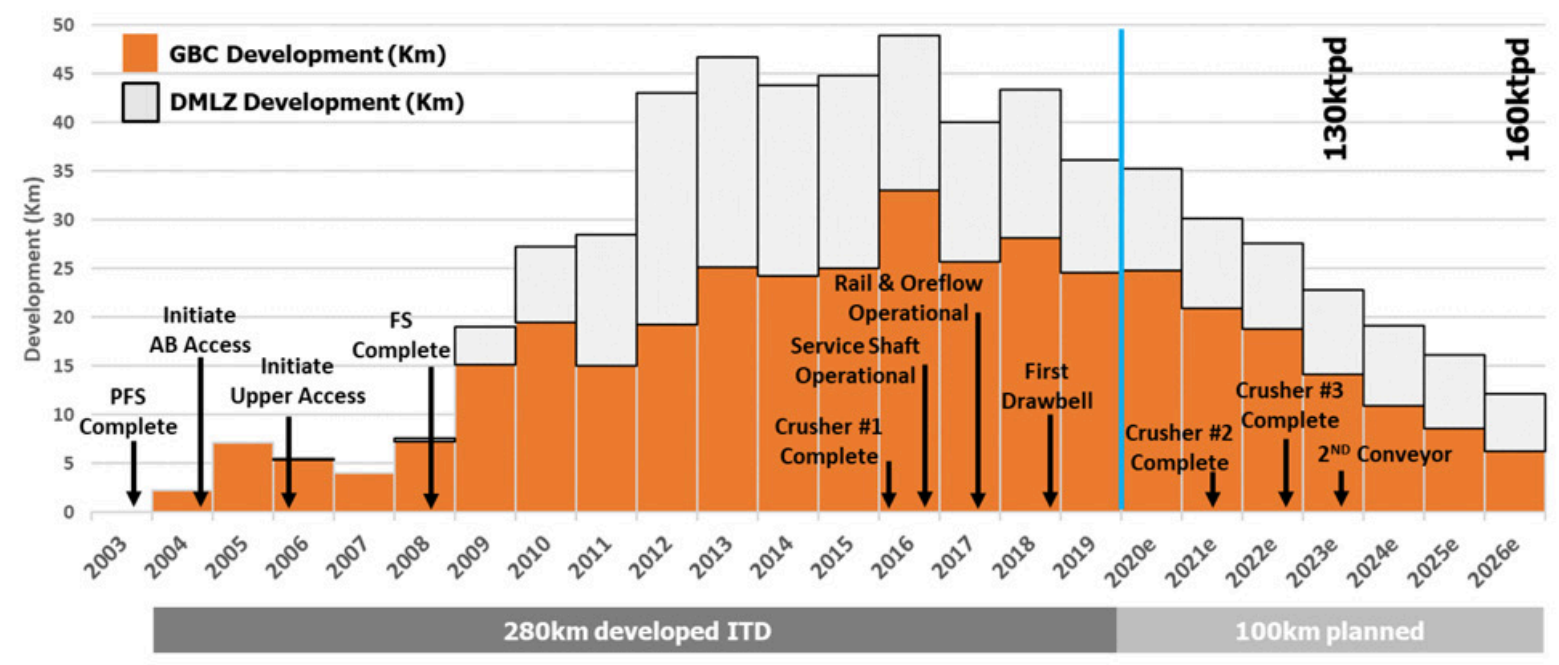

Figure 12 GBC mine development and critical infrastructure milestones

This is a large mine development and construction effort in several separate areas of the district, ramping up over a 15-year period through 2019. The engineering and operations teams were able to effectively collaborate and exchange mining resources between projects as needed, allowing for significant flexibility in the short term.

With the exception of the GBC Service Shaft, all of the major infrastructure construction was performed by PTFI construction crews. The majority of the development was completed using mining contractors with a long history of work at PTFI.

The GBC mine does not utilize ventilation shafts but instead has eight large diameter adits that serve as intake and exhaust plenums for the mine. This adds to the total horizontal development required but was a simpler and more cost-effective solution to a series of vertical shafts considering the extreme topography and required horizontal standoff from cave influence.

On December 15, 2018, the GBC fired the first drawbell, and by end the end of 2019, was producing 17 ktpd from 152 active drawpoints located over several production blocks (Brannon et al. 2020). It is anticipated the mine will achieve $130 \mathrm{ktpd}$ in 2023 and up to $160 \mathrm{ktpd}$ in 2026, as additional critical infrastructure is commissioned. The total capital expenditure on GBC and associated common infrastructure is estimated to be $\$ 6.7$ billion, including $\$ 4.6$ billion spent through year-end 2019 .

\subsection{Deep Mill Level Zone (DMLZ) - 2015-2041}

Access to the DMLZ was initiated in 2008 from a spur previously developed off the main AB Adit connection to the GBC and an additional critical path access for the conveyor declines was started in 2009. Figure 13 shows the timeline of mine development and critical infrastructure.

The DMLZ mine initiated caving in late 2015 and began a rapid drawbell opening process in the initial production block to the east. By the end of 2016, the mine had opened 35 drawbells, but it was apparent that mine-induced seismicity was a much larger issue than originally anticipated, and the required mitigation response significantly delayed the planned mine production ramp up. 


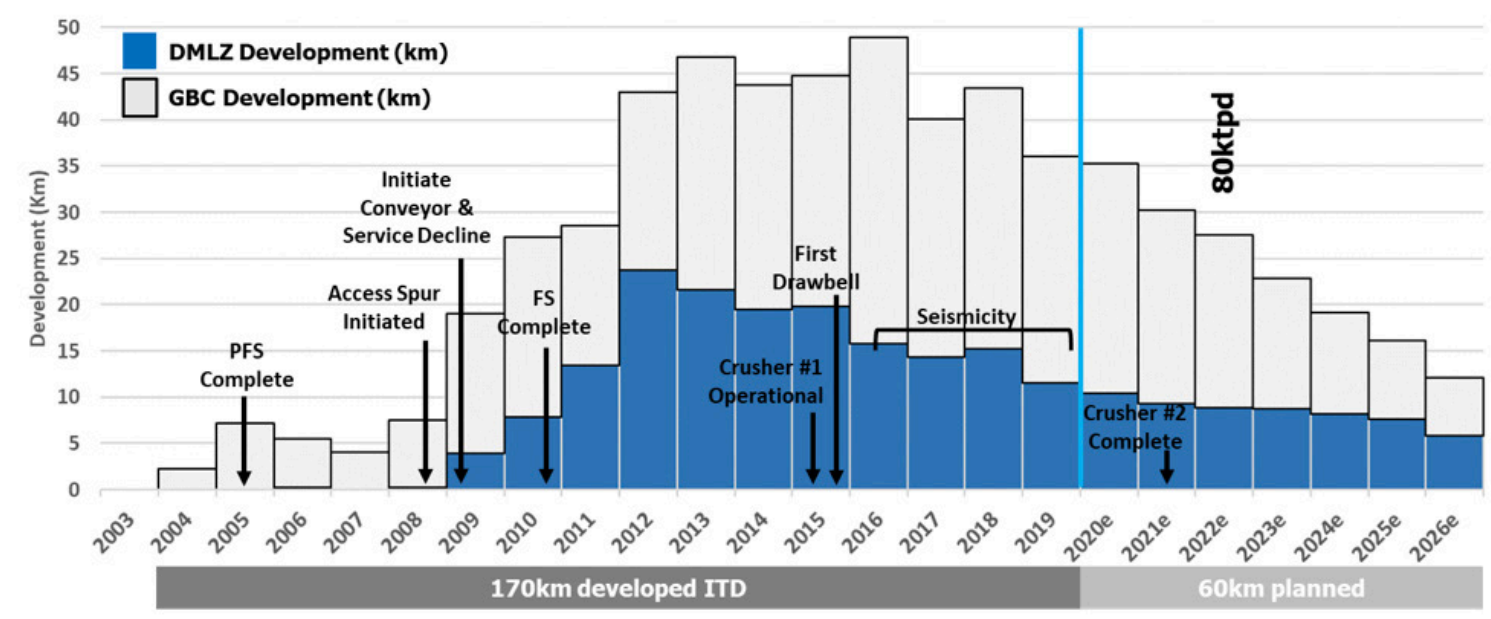

Figure 13 DMLZ mine development and critical infrastructure milestones

Once it was recognized that a significant seismic issue was present, several mitigation options were quickly identified through discussions with our consultants and industry peers. Several initiatives were identified and put in place almost immediately:

- The formation of an internal and external team of experts to review the seismicity and mitigation options

- The implementation of a micro-seismic based set of access protocols designed to keep personnel out of the seismically active areas based on blasting time or a certain set of seismic indicators or events

- A rapid shift in the type and quantity of ground support being installed with an early adoption of a mine-wide Gabion sill support concept (Kaiser 2017)

- A change in mining sequence to minimize extraction ratios ahead of the cave. This was a significant departure from the modified advance undercut process used in the DOZ for many years and added levels of complexity to the development and panel construction process that are still being resolved

- The rapid implementation of hydrofracturing of the rock mass (Nugraha et al. 2020). The first bespoke hydrofracturing pump was designed and ordered in 2017 and delivered in 2018. By the end of 2019, the DMLZ had three hydrofracturing pumps in operation supported by six diamond drill rigs. At the end of 2019, the mine had managed to emplace 5,800 fractures in the rockmass.

The DMLZ mine was developed and constructed in parallel with the GBC and shared the same resources and processes. By the end of 2019, the DMLZ mine had developed $170 \mathrm{~km}$ and undercut $68,000 \mathrm{~m}^{2}$ and had opened 180 drawpoints. The average production for 2019 was 9,800 tpd, and the DMLZ sustained production rates of 16,000 tpd in December 2019.

Mine development capital costs for the DMLZ underground mine are expected to be approximately $\$ 3.4$ billion, including $\$ 2.8$ billion incurred through end 2019.

\section{$5 \quad$ Strategic planning process}

With large underground mining projects envisaged to take 10-15 years to access, construct and initiate production followed by seven year ramp up, and with a total planned capital investment over $\$ 10$ billion, it was essential that a process was put in place to allow for continued updates, reviews and changes to the projects based on internal and external factors. 
The life of mine plan is updated quarterly and is based upon changes in mine schedules caused by both internal and external factors that affect production and development. This quarterly update of the lifeof-mine plans has been instrumental in recognizing, communicating and mitigating short and long-term issues that materially impact the mine forecasts. This quarterly review and updating of the mine plans allow for clear and regular updates to senior management and the project partners. It also allows for rapid responses to mitigate any issues raised, and these are typically made quickly and executed promptly.

\subsection{Life of mine strategic planning}

Figure 14 shows the LOM plan used in 2002 when the future underground mine studies were initiated compared with the actual tonnes produced through 2019 and the plan going forward. As noted previously, PTFI underwent a significant growth in reserves over time. This has driven the mine plan, as adjustments were made to maximize value. This reserve addition above the 2002 plan is shown in Figure 14 along with the adjustments made to accommodate both labour disruptions and government mandated export restrictions between 2011 and 2017.

Adjustments made to the strategic plan managed to minimize the unplanned disruptions as much as possible and also reduced the fairly significant "gap" in production anticipated in the 2002 LOM plan between 2015 and 2020. Additional reserve tonnes have filled out PTFI's mining capacity starting in 2023 with the primary limitation being the end of the IUPK in 2041 and overall annual throughputs. PTFI has 2.68 billion tonnes of ore in resource, with the primary constraint being the timing of the IUPK that ends in 2041.



Figure 142002 LOM production plan versus actual production and the 2019-2041 forecast

\subsection{Project controls and processes}

With such long-term projects, the original feasibility studies become less relevant over time as additional reserves are added, improved geological information becomes available and changes to the schedule start to impact the project timing. Several key processes were created to help manage the large underground expansion projects and provide consistent and regular methods of assessing progress.

\subsubsection{Mine design and approvals}

The corporate engineering team located in the U.S., creates the life-of-mine designs and also generates the medium-term development and ground support designs that were historically and typically performed at the mine site. These designs tie into an integrated scheduling package that generates the mine development and support activities for each UG mine down into a detailed work breakdown structure (WBS).The designs are generated through regular collaboration with the PTFI teams in Papua, Indonesia. The site team then takes the medium-term drawings and breaks them down into smaller short-term executable work packages used directly by the operations teams. 
The design database uses a system of distributed architecture that keeps a single and consistent version of the mine design and schedule available to all users in both time zones. There is a 16-hour time difference between the two teams with a three-hour window of overlap for discussions. This effectively extends the engineering workday into two overlapping shifts. The designs are circulated throughout all of the stakeholders for digital approval. These types of systems are now more commonplace in the industry and are essential with up to 5-6 km of mine designs being produced monthly, which can represent approximately 60 percent of capital expenditures.

\subsubsection{Management of change}

In such complex and long-term projects, there are several generations of new engineering and operational personnel that work on the project and may not necessarily have all of the history associated with the design and schedule adjustments made over time. Often, impactful changes were made without fully understanding the larger implications or fully communicating to the broader team. These changes were often not fully documented and typically relied on personal emails as both the approvals and storage system.

In order to help control these changes, a change request (CR) system was setup via the existing online approval process system and independent of email. These CRs are typically around major design or timing changes that would materially impact the project and require input from numerous stakeholders. A standard CR template was created with key metadata such as cost and schedule impacts plus a base list of critical stakeholders who are always included in every decision.

The change request details along with the CR template are sent to all of the stakeholders for parallel review, comment and either approval or rejection. This parallel review enables open discussion at all levels of stakeholders and greatly accelerates the process versus the typical in-series hierarchical approvals approach. Any fatal flaws are called out early on and revisions made fairly quickly in the approvals process. The CR can also be forwarded to others as needed. All of the comments, concerns and revisions are logged and stored with the approved CR. To date, the change request system has logged over 600 CRs, and this library of change is available to all users as part of the project history.

The CR system has greatly increased the collaboration and communications between the different teams and often results in lively debate between the different stakeholders. The average CR decision time is 19 days, including some significantly delayed outliers. The bulk of the CRs are typically decided within two to three weeks. The CR process is now widely accepted by the project teams and adhered to, for the most part. It is worth noting that any mobile equipment or additional costs required as part of a change will not be included in the next quarter's capital forecast model without an approved CR.

\subsubsection{Cost controls}

The WBS data and schedules generated from the mine design process is uploaded into a comprehensive cost-modelling database utilizing common input cost libraries and constructs, actual cost data and any CR impacts. The models apply earned value principles and are used to analyse cost trends, scope changes and timing impacts. This is compiled monthly and reviewed quarterly with comparisons to the annual budget and previous quarter predictions.

The quarterly forecast reviews have been a standard since 2009 and are held at site with all of the stakeholders. The format has changed over the intervening time, but the key review elements of safety, metal production, costs and expansion project progress have been consistent throughout.

\subsubsection{Rapid response to changing conditions}

PTFI has a history of reacting quickly to challenges and producing safe and effective solutions that are rapidly implemented. This has been a consistent part of the PTFI history and endures today. In the 1980s, the GBT Mine Manager was quoted as saying: 
"Management is open to suggestion and changes, and demonstrates a continuing confidence in the operating staff's ability to overcome the caving problems and garner productivity improvements."

The processes in place keep all levels of management well informed of project progress and any challenges that are on the horizon. This level of communication and involvement allows for rapid decision-making and continuous forward progress.

\section{Conclusions}

The Grasberg mining district has a history of rapid growth and expansion and has been operating caving mines since the 1980s. Reserve growth outpaced production depletion for many years, and since the start of the future underground expansion plans in 2002, there has been significant growth in the overall reserves and resources.

The PTFI minerals district has undergone several significant delays from labour issues, concentrate export restrictions and a variety of technical challenges. The life-of-mine schedule has been constantly adjusted to maximize value and mitigate the impact of these changes wherever possible. The PTFI team reacts quickly to challenges and rapidly implements safe and effective solutions.

With the closure of the open pit in 2019, future production is scheduled from the underground operations. Planning for these UG expansion projects began in 2002, with access initiated in 2004. Now, it is ramping up towards production rates of 200-250 ktpd. Over two thirds of the total mine development is complete and all of the initial key infrastructure is in place. Both DMLZ and GBC have initiated caving and are producing ore with consistent rates achieved between 16-17 ktpd at year-end 2019, respectively. From inception to date, the two large expansion projects, GBC and DMLZ, have cost $\$ 7.4$ billion out of an estimated total of $\$ 10.1$ billion on the UG projects. Additional capital is planned for supporting infrastructure.

PTFI has significant ore resources, constrained by the timing of the IUPK. This constraint has an impact on the longer-term decisions on capital spending for future projects. Large future projects like the KL mine are currently under review to try and optimize value given the throughput and timing constraints.

A comprehensive mine design, scheduling and project controls system is in place and this promotes collaboration and communication between the key stakeholders. The system, for the most part, is very effective, but does require regular reviews and reminders.

The PTFI mining district is embarking on a post pit era with several large volume caving operations underway and ramping up rapidly. Our workforce has extensive cave-mining experience and include many second-generation PTFI employees. We are able to attract the best engineers and operators to the mine site and have extensive and comprehensive training programs in place.

\section{Acknowledgement}

The authors wish to thank Freeport-McMoRan Inc. for permission to publish this paper and for their continued support and trust over the past two decades as these underground projects were envisioned, constructed and brought into production.

\section{References}

Brannon, C, Beard, D, Pascoe, N \& Priatna, A 2020, 'Development and Production Update of the Grasberg Block Cave Mine PT Freeport Indonesia', Proceedings of MassMin 2020, Santiago, Chile.

Coutts, BP Flint, D, Belluz, N, Susanto, H \& Edwards, A 1999, 'Geology of the Deep Ore Zone Ertsberg East Skarn System Irian Jaya, Indonesia', the 28th IAGI Annual Convention 1999, Jakarta, pp. 2-8. 
Dozy, JJ 1939, 'Geological results of the Carstensz expedition, 1936', Leidsche Geologische Mededelingen, vol. 11, pp. 68-131.

Hewitt, S, Sudjatmoko, Casten, T \& Brannon C 2008, 'Grasberg block cave access and logistics support systems', in H Schunnesson, E Nordlund (eds), Proceedings of MassMin 2008, Lulea, Sweden, pp. 471-480

Kaiser, P 2017, 'Ground control in strainbursting ground - a critical review and path forward on design principles', ed. J Vallejos, in Proceedings of the 9th International Symposium on Rockbursts and Seismicity in Mines, RaSiM9, Santiago, Chile, pp. 27-39

Mahayasa M, Widijanto E, Yuniar A \& Gautama R 2020, 'The Final Result of Slope Optimization Program at Grasberg Surface Mine, Papua - Indonesia', Proceedings of MassMin 2020, Santiago, Chile.

Nugraha, N, Bastiawarman R \& Edgar I 2020, 'Initial Setup of Hydraulic Fracturing in Deep Mill Level Zone (DMLZ) Underground Mine, PT. Freeport Indonesia', Proceedings of MassMin 2020, Santiago, Chile.

Priatna, A, Edgar, I, Prasetyo, R \& Wilkinson, M 2020, 'Deep Ore Zone Mine wet ore mining empirical learnings, mining process evolution and development pathway', Proceedings of MassMin 2020, Santiago, Chile.

Schwarz A, Leys C, Cloos, M, Widodo S, Kyle, R \& Sirait, J 2019, 'Grasberg Cu-Au-(Mo) Deposit: product of two overlapping porphyry systems', Society of Economic Geology, Volume on World Gold Deposits

Wilson, F 1977, 'The Ertsberg - A Case History of Mine Development', Jackling Lecture, Society of Mining Engineers, AIME annual meeting, vol.262, pp.81-86, 